Pesticides and other agrochemical were found to be within reach of farmers who get their supplies from agrochemical dealers at their farms and homes. Farmers who apply pesticides in mixtures were of the view that tank mixing was favourable because it saves time, labour and cost since more than one pesticide could be applied in a single supply. Farmers generally were aware of the potential adverse impacts of pesticide deposition on the environment but didn't know it have adverse health effect on human. Most farmers stored agrochemicals in multipurpose storage structures together.

\section{P-44 THE ASSOCIATION BETWEEN NIGHT SHIFT WORK AND CARDIOVASCULAR AND ENDOCRINE DISEASES IN HEALTHCARE WORKERS IN BULGARIA}

${ }^{1}$ Irina Cekova, Katya Vangelova. 'National Center of Public Health and Analyses, Bulgaria

\subsection{6/OEM-2021-EPI.173}

Introduction The prevalence of shiftwork is especially high with hospital healthcare workers. A number of epidemiological studies have found an association between night shift work, and cardiovascular (CVD) and endocrine diseases, involving circadian, behavior and social characteristics.

Objectives The aim of the study was to investigate the association between night shift work and cardiovascular and endocrine diseases in hospital healthcare workers in Bulgaria and possible mediating factors.

Methods The study included 2690 healthcare workers with an average age of $48.0 \pm 12.0$ years and an average length of service $24.8 \pm 12.7$ years, from 19 hospitals with $>150$ beds in Sofia, Bulgaria. A self-administered questionnaire was used to gather information about demographic, physical and behavioral characteristics, previous and current work schedules, and the health status of healthcare workers.

Results The worker group with the highest prevalence with CVD was ex-night shift workers (35.3\%), followed by night shift workers $(24.4 \%)$ and the lowest with day workers (16.3\%). The OR for developing a CVD for night workers was 1.98 (95\% CI: 1.26-3.13); and endocrine diseases, 1.33 (95\% CI: 0.83-2.12). The development of CVD was related to age, family history for hypertension and coronary heart disease, body mass index (BMI), heavy smoking and sleep disorders, while endocrine diseases with BMI, shift system, alcohol consumption and family history for diabetes.

Conclusion Data from our study strongly support the evidence for an increased risk and higher prevalence of cardiovascular and endocrine diseases in night shift workers. Actions for improvement of shiftwork organization and health promotion are needed for tackling CVD and endocrine diseases for a better health status of health care workers.

\section{P-46 INDICATORS OF ABSENTEEISM DUE TO MENTAL ILLNESS IN THE JUDICIAL SECTOR: A DESCRIPTIVE APPROACH OF A RETROSPECTIVE COHORT}

${ }^{1}$ Kionna Bernardes, Rita Fernandes, Bruna Melo. ${ }^{1}$ Federal University of Bahia, Brazil

\subsection{6/OEM-2021-EPI.174}

Introduction Sickness absence is characterized by individual's withdrawal from work, for reasons of health and can be indicator of existing problems with the context work, in addition to triggering consequences and damages for the worker and society. An analysis of sickness absence due to mental and behavioral disorders contributes to the dimensioning of the problem and to the search for factors related to work that are potentially stressful, in addition to favoring the identification of possible exposure scenarios for illness due to mental disorders, to which workers may have been submitted.

Objective To describe the indicators of sickness absence due to mental disorders of public servants in the judicial sector in Brazil in the period from 2011 to 2016.

Methods This is a retrospective cohort study on the casuistry of absenteeism. Workers who were on sick leave at the time of the study were excluded. The sociodemographic and occupational profile was observed, in addition to estimated epidemiological indicators (prevalences, cumulative incidence, prevalence ratios and risk ratios).

Results There was a total of 1023 events, with a greater number of episodes among servers with more than 10 years of service. The magnitude and occurrence of incident cases of absenteeism tended to decrease over the years, yet women were the most affected group, with prevalences higher than those of the men. Mood disorders, neurotic and stress-related disorders were the clinical diagnoses with the highest prevalences attributed to absenteeism.

Conclusion This approach and considerations are valid externally for the analysis of other services and pose challenges for the health services of the institutions, especially in the early detection of the risk of withdrawal and monitoring of working conditions.

\section{P-49 OCCUPATIONAL HAZARD EXPOSURES, SHIFTWORK AND PHYSICAL HEALTH OF FEMALE FACTORY WORKERS}

'Sophia Francesca Lu, Jinky Leilanie Lu. 'University of the Philippines Diliman, Philippines

\subsection{6/OEM-2021-EPI.175}

Objectives This study aimed to look into the association between occupational hazards and shift work with the frequency of occurrence of adverse physical health symptoms among 500 female factory workers in the Philippines.

Methods This is a meta-analysis of a database of a research study on female factory workers. Data on a wide range of socio-demographic, health and occupational characteristics were analyzed. The health data collected were the selfreported frequency of occurrence of various mental and physical health symptoms and injuries. Regressions were also used between factors affecting female worker's shiftwork and physical health.

Results Associations were observed between shift schedule, workload, sex, occupational risk, harassment, injuries, use of personal protective equipment, benefits, unions, employeremployee relations, and employee-employee relations, with the frequency of onset of physical health symptoms. The odds ratio for the association between shift schedule and occurrence of physical health symptoms was $1.82(0.66-4.97 ; \mathrm{p}=0.39)$ implying that female workers who worked in the evening were 1.82 times more likely to have frequent physical health symptoms. Having seminars on occupational health may modify the association between shift schedule and physical symptoms. In the final model, the ergonomic and occupational health factors that affected physical health were employeeemployee relations, harassment, workload, and work benefits. 